\title{
Gene drives as a response to infection and resistance
}

This article was published in the following Dove Medical Press journal: Infection and Drug Resistance

\section{Tuna C Hayirli' \\ Peter F Martelli²}

'Harvard Medical School, Boston, MA, USA; ${ }^{2}$ Department of Healthcare Administration, Sawyer Business School, Suffolk University, Boston, MA, USA
Correspondence: Peter F Martelli Department of Healthcare Administration, Sawyer Business School, Suffolk University, 120 Tremont St, Boston, MA 02108, USA

Tel +l 6173051939

Fax + I 6179944228

Email pmartelli@suffolk.edu
Abstract: Vector-borne infectious diseases continue to be a major threat to public health. Although some prevention and treatment modalities exist for these diseases, resistance to such modalities, exacerbated by global climate change, remains a fundamental challenge. Developments in genomic engineering technologies present a new front in battling vector-borne illnesses; however, there is a lack of consensus over the scope and consequences of these approaches. In this article, we use malaria as a case study to address the developments and controversies surrounding gene drives, a novel genomic engineering technology. We draw attention to the themes of infection control, resistance, and reversibility using a science and technology studies framework. Unlike other current prevention and treatment modalities, gene drives have the capacity to alter not only single organisms but also entire species and ecologies. Therefore, broader public and scientific engagement is needed to inform a more inclusive discussion between clinicians, researchers, policy makers, and society.

Keywords: CRISPR, gene drive, gene editing, vector-borne disease, STS, imaginaries

\section{Introduction}

Though it has been tens of centuries since the identification of malarial disease ${ }^{1}$ and a hundred years since the understanding of its transmission mechanism, ${ }^{2}$ malaria continues to be a major public health problem, despite options for treatment and prevention. Approximately 3.2 billion people are at risk of contracting the disease. In 2015, there were 214 million cases of malaria and 438,000 associated deaths around the globe. ${ }^{3}$ Sub-Saharan Africa suffers nearly $90 \%$ of all global malarial deaths, with more than two-thirds of those deaths in children under 5 years of age. ${ }^{3}$ Furthermore, models accounting for the impact of global climate change on mosquito populations project a net increase in at-risk populations. ${ }^{4} \mathrm{~A}$ correlation between concentrated areas of malaria and high poverty levels suggests a linkage between the disease and socioeconomic conditions, ${ }^{5}$ with the financial costs of the disease undoubtedly affecting local economies.

The best approach to control a disease is by optimizing a mix of prevention and early, effective treatment. ${ }^{6}$ In recent years, rapid diagnosis examinations and Artemisinin-Based Combination Therapies (ACT) have been the frontline tools for the diagnosis and treatment of malaria. However, ACT resistance is an imminent concern, with significant negative economic and social impact ${ }^{7}$ and has been on the rise in countries such as Cambodia and Thailand. ${ }^{3}$ Long-lasting insecticide nets, targeted indoor insecticide spraying, larval source management, and newly emerging 
recombinant vaccines are some of the tools and techniques used to combat mosquito-borne infectious diseases. Yet the need for novel methods of prevention and treatment is ever increasing due to the rise of antimalarial, antiviral drug, and insecticide resistance. ${ }^{8}$ Some have begun to advocate for the development of genomic engineering and synthetic biology tools to eradicate mosquito-borne diseases by rearing genetically modified mosquito vectors in laboratories to be released into the wild..$^{9,10}$

\section{Gene editing and gene drive technologies}

The recent discovery and development of clustered regularly interspaced short palindromic repeats (CRISPR) has begun a new era in precise methods of genomic editing. The CRISPR technology, often analogized to molecular scissors, functions like a prokaryotic immune system. First, a synthetic single guide RNA (sgRNA) and the preferred endonuclease, such as Cas9, are introduced into a cell. ${ }^{11}$ The engineered sgRNA then tags the targeted DNA sequence, guiding the cleaving enzyme to the location of the edit. The cell recognizes the DNA cut performed by the nuclease and initiates repair mechanisms. The repair system enables the deletion, revision, or addition of nucleotide sequences, thereby inducing a change in the expression and function of genes.

The possibilities of utilizing gene editing technologies are vast and have attracted massive interest from the biotechnology industry. However, the application of CRISPR with gene drives is more complex and controversial, necessitating scientific, social, and political debate. ${ }^{12}$ The gene drive concept is based on selfish genetic elements, or self-replicating pieces of DNA that guarantee their own passage on to the next generation. ${ }^{13}$ Selfish genetic elements break away from the Mendelian hereditary framework of alleles passing on with $50 \%$ chance. As defined by the National Academies of Sciences, Engineering, and Medicine, gene drives enhance the ability of alleles to pass on to the next generation:

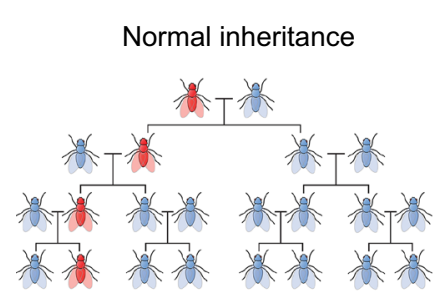

Altered gene does not spread
Thus, the result of a gene drive is the preferential increase of a specific genotype, the genetic makeup of an organism that determines a specific phenotype (trait), from one generation to the next, and potentially throughout the population. ${ }^{14}$

Gene drive technologies, then, are a set of molecular tools that facilitate ecological engineering - a term discussed below - by increasing the likelihood of a genetic element to pass on from one generation to the next and spread through a population (Figure 1).

The first conception of gene drives goes back to the 1960s when a group of scientists proposed that if "the $Y$ chromosome could be freed from the inhibitory control of the rest of the genome" - that is, control of the Mendelian rule of a $50 \%$ chance of inheritance - then a population could be driven to extinction by eliminating all females. ${ }^{15}$ It took until 1992 for scientists to suggest that transposons could be used to drive a desired gene into the genetic pool of a population. ${ }^{16} \mathrm{~A}$ few years after the publication of the concept, Austin Burt, from London's Imperial College, suggested the use of selfish genes, homing endonuclease genes, to drive genetic alterations into populations. ${ }^{17} \mathrm{~A}$ decade after Burt's proposal, Kevin Esvelt, now at the MIT Media Lab, catalyzed the idea of combining gene drives with CRISPR. ${ }^{18}$

CRISPR gene drives make use of CRISPR's DNA revision mechanism by copying engineered nucleotide sequences into homologous chromosomes, thereby guaranteeing the inheritance of edited genes in all offspring. ${ }^{19}$ Since the initial proposal by the Burt and Esvelt laboratories, studies have demonstrated the use of the gene drive concept in yeast, ${ }^{20}$ fruit flies, ${ }^{21}$ and mosquitoes. ${ }^{22-25}$ These experiments have taken place in contained laboratories; nonetheless, gene drive technologies may soon be used in the environment to genetically engineer populations, embedding into and changing the already complex social and technical contexts of disease in unique ways.

\section{Malaria and beyond}

Researchers and philanthropists have begun teaming up to develop gene drives for mosquito populations, with the Bill

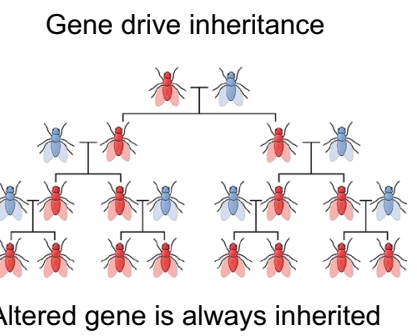

Figure I An illustration of inheritance through gene drive technology. ${ }^{46}$

Note: Adapted from Walter M. Gene Drive. Wikipedia, The Free Encyclopedia. September25, 2017. Available from: https://en.wikipedia.org/wiki/File:Gene_Drive.png. Creative Commons Attribution-Share Alike 4.0 International license. 
and Melinda Gates Foundation donating over \$75 million to Target Malaria, a non-profit vector control research alliance dedicated to finding a gene drive solution to the global malarial problem. ${ }^{26}$ Eradication of malaria is the initial and main motivator for this project, as evidenced by Burt's sentiment in his seminal paper:

Some species - a relatively small number - cause substantial harm to the human condition ... Many such species have long been targets of population control, with varying degrees of success, but some species are still beyond control by current methods, and new approaches are required. ${ }^{17}$

Since that publication, researchers have developed new genetic approaches to address malaria according to this framing of the problem. In other words, the solutions pursued derive from how the problem is defined and envisioned. Therefore, the imagined solutions "to reduce the vectorial capacity" of mosquitoes include:

1. affecting the survival or reproductive capacities of mosquitoes;

2. shifting the sex ratio;

3. making female mosquitoes prefer feeding on species other than humans;

4. preferentially killing infected female mosquitoes; and

5. disabling mosquitoes from hosting parasites. ${ }^{27}$

Yet the scope of gene drives extends beyond the grand problem of malaria or even other mosquito-borne illnesses. As Esvelt notes:

In addition to altering populations of insects to prevent them from spreading disease, this advance [ie, gene drives] would represent an entirely new approach to ecological engineering with many potential applications relevant to human health, agriculture, biodiversity, and ecological science. ${ }^{18}$

Initially imagined as a new technology to eradicate a disease that is not sufficiently addressed by current methods, gene drives are now seen to open the door to "ecological engineering." Min et al provide key classifications of the types of drives that can be developed to engineer ecologies. ${ }^{29}$ The first distinction is between local and standard drive systems. As the name implies, standard drives are designed to genetically alter an entire species without setting any temporal or geophysical limitations to their spread. They make use of a single element that contains CRISPR and the modification information. For instance, Kyrou et al have already demonstrated a method of engineering a construct targeting the $A g d s x$ gene which led to "total population collapse" in caged mosquitoes. ${ }^{28}$
Alternately, local drives, such as daisy drives, are meant to achieve local and transient population suppression. Daisy drive systems, also known as split drives, instead contain split up portions of CRISPR that require sequential action for the drive to operate: element $\mathrm{A}$ drives element $\mathrm{B}$, which drives element $\mathrm{C}$, and so on until the final element, which does not drive any others. ${ }^{30}$ As gene drives are limited to be used in sexually reproducing organisms, the elements can be lost.

The local vs global distinction is of utmost importance, as it is not trivial which community in the world is the first to confront the uncertainties and risks that come with environmental releases of altered organisms. Historically, low- and middle-income countries have borne higher risks by having such field trials imposed on them by well-intentioned technologists from richer countries. Oxitec, a company that produces genetically modified (non-gene drive) mosquitoes, provides a recent example. The company had already released their mosquitoes in Brazil and Panama and had plans to release their product in the Florida Keys. The Florida Board of Elections included a non-binding vote on the use of the genetically modified mosquitoes in the November 2016 general elections. ${ }^{31}$ In Monroe County, which includes all the Florida Keys, $57.78 \%$ of the 40,505 votes cast supported the release. On the other hand, illustrating a typical NIMBY ("not in my back yard") pattern, of the 643 voters in Key Haven, the projected site of the release, only $34.84 \%$ voted in support while $65.16 \%$ voted against the release.

As the application of gene drive technologies is not limited to mosquitoes, similar public controversies will certainly arise. In addition to vector-borne disease control, other potential spheres of use include, but are not limited to, developing novel pesticides and herbicides, managing pests, and eradicating invasive species. ${ }^{18}$ Recent attempts to modify mice with gene drives demonstrate not only the possibility but also the appeal to broaden the technology's scope. ${ }^{32,33}$ While gene drive use on mammals remains on the horizon, further laboratory experimentation, as well as public ethical and legal deliberation are in sight.

Deliberations on ethical questions raised by the release of genetically modified organisms have resulted in suggestions for having communities permit field trials and asking for their help in designing trials. ${ }^{34}$ Target Malaria proposes using gene drives in Burkina Faso, Mali, and Uganda ${ }^{35}$ as an approach to "provide area-wide control, and therefore protection [from adverse consequences] without obvious biases relating to a person's age, wealth or education." ${ }^{36}$ All areas, however, do not contain heterogeneous mixtures of persons. Age, wealth, education, and socioeconomic status are all commonly known 
determinants of health that are dependent on and covariant with the place of residence. Hence, area-wide control may not necessarily provide bias-less protection. Furthermore, claims that "local communities can give high levels of support to the trials once they are explained to them" 36 may not always hold true. In using global drives, where extinction of a species is not just a potential byproduct but a goal, who becomes the relevant local community? What aspects of the trials are explained to individuals, and how well equipped are these individuals to understand complex molecular and ecological models, ask crucial questions, and make such ambitious choices about uncertain futures?

\section{Reverse if we don't like it?}

In addition to local and standard drives, other classifications of drives are imagined in the battle with malaria, which is portrayed as "such a terrible scourge that any possible combination of unexpected effects would arguably be preferable to the disease itself." 29 Precision drives directly alter genomes so that the effects of the drive are only realized in targeted organisms. ${ }^{37}$ Alteration drives make specific changes, either by adding or by making edits to genes. ${ }^{29}$ Suppression drives reduce the number of organisms in a population, often using previously mentioned methods of reducing vectorial capacities. ${ }^{29}$ Immunizing drives prevent the spread of unwanted genes by preemptively altering genetic sequences to block the effects of precision drives. ${ }^{29,37}$

Experts, convened by the Foundation for the National Institutes of Health and the International Life Sciences Institute Research Foundation to discuss the development and use of such drives for malaria in Africa, concluded that newly introduced genes would not horizontally transfer to humans or other species and that predators of mosquitoes would not be significantly impacted due to the availability of other prey. ${ }^{38}$ These experts also noted that while the use of gene drives "should be considered as a complementary strategy to other vector control methods and malaria mitigation strategies," techno-optimism from relying on a technology to be sufficient alone in eradicating malaria is "unrealistic," as risks and safety concerns remain.

The development of resistance to gene drives is an interesting justification for the safety of their use. The combinations of molecular genome repair mechanisms as well as evolutionary selective mechanisms could lead to the rise of resistant alleles, forming a sort of counter-drive system. ${ }^{39,40}$ Resistance to gene drives is seen to be inevitable, ${ }^{29}$ and solutions to the development of resistance to this novel technology will be necessary. Another contributor to the safety argument of gene drives is reversibility. Reversal drives reverse the genomic changes made in organisms, essentially reversing previously performed edits. ${ }^{37}$ Reversal drives can either be sequence-reversible systems, which undo the molecular changes to return the genome sequence to what it was before, or trait-reversible systems, which reverse phenotypic changes without returning the sequence to its state before the intervention. ${ }^{29}$ However, the reversibility of genetic changes is not an all-encompassing form of reversing. There are no recalls or reset buttons for irreversible damages to health and the environment as a result of undesired biological releases. The attitude "if we do not like it, we can change it" is unrealistic at the ecological level and downplays the magnitude of ecological and epidemiological changes that may occur rapidly.

Fortunately, there is a wide agreement within the community of gene drive researchers that meaningful public discourse is predicated on the open and transparent communication of their data, models, results, and research agendas in a format understandable to both peers and the public. ${ }^{18}$ Along the lines of a Kuhnian paradigm shift, thought leaders in the gene drive community are arguing that the potential consequences of gene drives should be powerful enough to incentivize scientists to be transparent about their research agendas, opening up the "black-box" of science. ${ }^{41,42}$

\section{Conclusion}

In the spirit of more inclusive discussion, we offer our perspectives to an international audience that not only contemplates the prevention and treatment of infection but also curtails emerging resistance to interventions. We make use of the sociotechnical imaginary framework, founded in the tradition of Science and Technology Studies (STS), to guide our analysis of current discussions. Sociotechnical imaginaries are "collectively held, institutionally stabilized, and publicly performed visions of desirable futures, animated by shared understandings of forms of social life and social order attainable through, and supportive of, advances in science and technology." 43 Through the STS lens, one can see that researchers, technologists, and policy makers are infusing the development of gene drives with what they judge and imagine to be important, and these technologies will influence society, health, and the environment in a recursive fashion.

While some view novel genomic engineering technologies to be the silver bullet in fighting vector-borne infectious diseases, these technologies will also face resistance - both social and biological. To date, principles of safety, accountability, transparency, governance, and public engagement 
have been explicitly supported. ${ }^{44}$ We argue that what is needed, then, is to develop technologies of humility ${ }^{45}$ and proceed with an awe of complexity and caution under uncertainty. For researchers studying vector-borne diseases, this entails clearly elaborating the goals and assumptions of the research with respect to the scope and reversibility of the intervention and which communities, if applied, would be subject to the consequences. For clinicians and facilities addressing these diseases, it entails being advocates at the local level and playing a key role as partners in the surveillance of new, unexpected presentations. For both the parties, it suggests that these new technologies demand broader participation across the scientific and general populations in order to guide this technology into effective application.

\section{Disclosure}

The authors report no conflicts of interest in this work.

\section{References}

1. Briggs H. DNA clues to malaria in ancient Rome. $B B C$ News. Available from: http://news.bbc.co.uk/2/hi/science/nature/1180469.stm. Accessed September 21, 2018.

2. Guinovart C, Navia MM, Tanner M, Alonso PL. Malaria: burden of disease. Curr Mol Med. 2006;6(2):137-140.

3. World Health Organization. World malaria report 2015. Available from: http://www.who.int/malaria/publications/world-malaria-report-2015/ report/en/. Accessed September 21, 2018.

4. Martens WJ, Niessen LW, Rotmans J, Jetten TH, McMichael AJ. Potential impact of global climate change on malaria risk. Environ Health Perspect. 1995;103(5):458-464.

5. Sachs J, Malaney P. The economic and social burden of malaria. Nature. 2002;415(6872):680-685.

6. Centers for Disease Control and Prevention [website on the Internet]. Malaria. [updated 2015 Oct 7]. Available from: https://www.cdc.gov/ malaria/about/disease.html. Accessed September 21, 2018.

7. Porter-Kelley JM, Cofie J, Jean S, Brooks ME, Lassiter M, Mayer DG. Acquired resistance of malarial parasites against artemisinin-based drugs: social and economic impacts. Infect Drug Resist. 2010;3:87-94.

8. World Health Organization. Global technical strategy for malaria 2016-2030. Available from: http://www.who.int/malaria/publications/ atoz/9789241564991/en/. Accessed September 21, 2018.

9. Alphey L, Alphey N. Five things to know about genetically modified (GM) insects for vector control. PLoS Pathog. 2014;10(3):e1003909.

10. Gabrieli P, Smidler A, Catteruccia F. Engineering the control of mosquito-borne infectious diseases. Genome Biol. 2014;15(11):535.

11. Reis A, Hornblower B, Robb B, Tzertzinis G. CRISPR/Cas9 and targeted genome editing: a new era in molecular biology. $N E B$ Expressions. 2014;1:3-6.

12. Pennisi E. SCIENCE AND SOCIETY. Gene drive turns mosquitoes into malaria fighters. Science. 2015;350(6264):1014.

13. Burt A, Trivers R. Genes in Conflict: The Biology of Selfish Genetic Elements. Cambridge, MA: The Belknap Press of Harvard University Press; 2006.

14. National Academies of Sciences, Engineering, and Medicine. Gene Drives on the Horizon: Advancing Science, Navigating Uncertainty, and Aligning Research with Public Values. Washington, DC: National Academies Press; 2016.

15. Curtis CF. Possible use of translocations to fix desirable genes in insect pest populations. Nature. 1968;218(5139):368-369.
16. Kidwell MG, Ribeiro JM. Can transposable elements be used to drive disease refractoriness genes into vector populations? Parasitol Today. 1992;8(10):325-329.

17. Burt A. Site-specific selfish genes as tools for the control and genetic engineering of natural populations. Proc Biol Sci. 2003;270(1518):921-928.

18. Esvelt KM, Smidler AL, Catteruccia F, Church GM. Concerning RNA-guided gene drives for the alteration of wild populations. Elife. 2014;3:e03401.

19. Sander JD, Joung JK. CRISPR-Cas systems for editing, regulating and targeting genomes. Nat Biotechnol. 2014;32(4):347-355.

20. Dicarlo JE, Chavez A, Dietz SL, Esvelt KM, Church GM. Safeguarding CRISPR-Cas9 gene drives in yeast. Nat Biotechnol. 2015;33(12):1250-1255.

21. Gantz VM, Bier E. Genome editing. The mutagenic chain reaction: a method for converting heterozygous to homozygous mutations. Science. 2015;348(6233):442-444.

22. Windbichler N, Menichelli M, Papathanos PA, et al. A synthetic homing endonuclease-based gene drive system in the human malaria mosquito. Nature. 2011;473(7346):212-215.

23. Gantz VM, Jasinskiene N, Tatarenkova O, et al. Highly efficient Cas9mediated gene drive for population modification of the malaria vector mosquito Anopheles stephensi. Proc Natl Acad Sci U SA. 2015;112(49): E6736-E6743.

24. Li M, Bui M, Yang T, Bowman CS, White BJ, Akbari OS. Germline Cas9 expression yields highly efficient genome engineering in a major worldwide disease vector, Aedes Aegypti. Proc Natl Acad Sci USA. 2017;114(49): E10540-E10549.

25. Hammond A, Galizi R, Kyrou K, et al. A CRISPR-Cas9 gene drive system targeting female reproduction in the malaria mosquito vector Anopheles gambiae. Nat Biotechnol. 2016;34(1):78-83.

26. Regalado A. Bill Gates Doubles His Bet on Wiping Out Mosquitoes with Gene Editing. MIT Technology Review; 2016. Available from: https:// www.technologyreview.com/s/602304/bill-gates-doubles-his-bet-onwiping-out-mosquitoes-with-gene-editing/. Accessed September 21, 2018.

27. Burt A, Coulibaly M, Crisanti A, Diabate A, Kayondo JK. Gene drive to reduce malaria transmission in sub-Saharan Africa. J Responsible Innov. 2018;5(Suppl 1):S66-S80.

28. Kyrou K, Hammond AM, Galizi R, et al. A CRISPR-Cas9 gene drive targeting doublesex causes complete population suppression in caged Anopheles gambiae mosquitoes. Nat Biotechnol. 2018;36: 1062-1066.

29. Min J, Smidler AL, Najjar D, Esvelt KM. Harnessing gene drive. $J$ Responsible Innov. 2018;5(supp1):S40-S65.

30. Noble C, Min J, Olejarz J, et al. Daisy-chain gene drives for the alteration of local populations. bioRxiv [serial on the Internet]. $2016 \mathrm{Jun}$; [32 p.]. Available from: https://doi.org/10.1101/057307. Accessed September $21,2018$.

31. Monroe County Supervisor of Elections [webpage on the Internet]. Monroe County Florida 2016 General Election Unofficial Results [updated 2016 Nov 14; cited 2016 Nov 18]. Available from: https:// web.archive.org/web/20161118125214/http://enr.electionsfl.org:80/ MON/Summary/1662/. Accessed September 21, 2018.

32. Grunwald HA, Gantz VM, Poplawski G, Xu XS, Bier E, Cooper KL. Super-Mendelian inheritance mediated by CRISPR/Cas9 in the female mouse germline. bioRxiv [serial on the Internet]. $2018 \mathrm{Jul}$ [11 p.]. https://doi.org/10.1101/362558. Accessed October 25, 2018.

33. Callaway E. Controversial CRISPR 'gene drives' tested in mammals for the first time. Nature. 2018;559(7713):164.

34. Neuhaus CP, Caplan AL. Ethical lessons from a tale of two genetically modified insects. Nat Biotechnol. 2017;35(8):713-716.

35. Target Malaria [homepage on the Internet]. Available from: http:// targetmalaria.org/. Accessed September 21, 2018.

36. Burt A. Heritable strategies for controlling insect vectors of disease. Philoso Trans R Soc B Biol Sci. 2014;369(1645):20130432.

37. Oye KA, Esvelt K, Appleton E, et al. Regulating gene drives. Science. 2014;345(6197):626-628. 
38. Roberts A, Andrade PP, Okumu F, et al. Results from the Workshop "Problem Formulation for the Use of Gene Drive in Mosquitoes". Am J Trop Med Hyg. 2017;96(3):530-533.

39. Prowse TAA, Cassey P, Ross JV, Pfitzner C, Wittmann TA, Thomas P. Dodging silver bullets: good CRISPR gene-drive design is critical for eradicating exotic vertebrates. Proc Biol Sci. 2017;284(1860):20170799.

40. Bull JJ. Lethal gene drive selects inbreeding. Evol Med Public Health. 2017;2016(1):1-16.

41. Esvelt K. Gene editing can drive science to openness. Nature. 2016; 534(7606):153.

42. Oye KA, Esvelt KM. Gene drives raise dual-use concerns--response. Science. 2014;345(6200):1010-1011.
43. Jasanoff S, Kim SH, editors. Dreamscapes of Modernity: Sociotechnical Imaginaries and the Fabrication of Power. Chicago: University of Chicago Press; 2015.

44. Emerson C, James S, Littler K, Randazzo FF. Principles for gene drive research. Science. 2017;358(6367):1135-1136.

45. Jasanoff S. Technologies of humility: Citizen participation in governing science. Minerva. 2003;41(3):223-244.

46. Walter M. Gene Drive. Wikipedia, The Free Encyclopedia. September 25, 2017. Available from: https://en.wikipedia.org/wiki/File:Gene_ Drive.png. Accessed October 26, 2018.
Infection and Drug Resistance

\section{Publish your work in this journal}

Infection and Drug Resistance is an international, peer-reviewed openaccess journal that focuses on the optimal treatment of infection (bacterial, fungal and viral) and the development and institution of preventive strategies to minimize the development and spread of resistance. The journal is specifically concerned with the epidemiology of antibiotic
Dovepress

resistance and the mechanisms of resistance development and diffusion in both hospitals and the community. The manuscript management system is completely online and includes a very quick and fair peerreview system, which is all easy to use. Visit http://www.dovepress.com/ testimonials.php to read real quotes from published authors.

Submit your manuscript here: https://www.dovepress.com/infection-and-drug-resistance-journal 